\title{
POBOACIÓN, EMPREGO EMIGRACIÓN NAS BISBARRAS DE GALICIA: 2011-2017 E PERSPECTIVAS
}

María-Carmen GUISÁN

Facultade Económicas da USC, Santiago de Compostela, mcarmen.guisan@usc.es Resumo Galicia é unha rexión do Norte de España con excelentes factores que contribúen á calidade de vida pero con insuficientes empregos e salarios, polo que se enfronta con problemas de perda de poboación en moitas bisbarras. Analizamos os movementos de emigración interior e exterior. A poboación xubilada contribúe coas súas rendas a manter a vitalidade en moitas zonas, pero é preciso tamén atraer á poboación en idade laboral a través da creación de emprego. No período 2011-2017 só 11 das 53 bisbarras de Galicia tiveron algún incremento do emprego e só tres (A Coruña, Santiago e Pontevedra) tiveron un incremento de poboación. O estudo inclúe un modelo econométrico, que amosa 0 impacto positivo e significativo do emprego sobre o incremento de poboación, estimado con datos das 53 bisbarras de Galicia. Recomendamos incrementar a converxencia do desenvolvemento industrial de Galicia cara os niveis de rexións europeas máis avanzadas. JEL codes: C5, J2, O15, R1, R23

Palabras chave: Galicia, España, Emprego, Demografía, Migracións internas e externas, desenvolvemento local, desenvolvemento rexional Population, Employment and Migration in Galician Counties: 1981-2017 and Prospects

Abstract Galicia is a region in Northern Spain with excellent conditions for a good standard of life, yet facing the problem of population loss in many counties, due to low wages and the lack of creation of sufficient jobs. This leads to internal and external emigration. The retired population contributes, with their income, to maintain vitality in many of these counties, but it is also necessary to attract a working-age population through the creation of employment. In the period 2011-2017 only 11 out of the 53 counties of Galicia have experienced an increase in employment, and only three (A Coruña, Santiago and Pontevedra) have had an increase of population. The study includes an econometric model that shows the positive impact of employment on the population increase at a county level. We recommend to increase the convergence of industrial development in Galicia to the levels of more advanced regions in Europe.

Keywords: Galicia, Spain, Employment, Demography, Internal and External Migrations, Local Development, Regional Development.

\section{Introdución}

Galicia é unha rexión con excelentes factores que contribúen á calidade de vida pero con insuficiente creación de emprego. O obxectivo deste estudo é analizar e impulsar o desenvolvemento comarcal de Galicia, mediante a creación de empregos que garanticen o asentamento poboacional e unha renda per cápita axeitada.

A sección 2 presenta unha síntese da evolución da poboación, o emprego nas provincias galegas ao longo do século XX e, en especial, no período 1967-2017, a evolución do emprego e a renda per cápita de Galicia nas últimas décadas, así como os movementos migratorios co exterior da rexión. Na sección 3 analizamos a evolución da poboación a nivel comarcal e presentamos modelos econométricos que relacionan a poboación comarcal e o emprego. A sección 5 presenta as principais conclusións, as cales insisten na grande importancia que ten o impulso da industria e/ou o turismo para 0 desenvolvemento dos sectores de servizos, con obxecto de aumentar a calidade de vida dos galegos (salarios, servizos públicos, etc.) e para evitar a emigración forzosa de miles de persoas que non atopan un traballo conforme á súa formación. 


\section{Evolución da poboación, o emprego, a renda e as migracións en Galicia}

Evolución da poboación a nivel provincial 1900-2017

Durante o século XX varios estudos, como os que se citan na bibliografía, ocupáronse da análise das perspectivas demográficas de Galicia.

Os investigadores constataban un crecemento moderado na primeira metade do século, nunha proporción menor que a do conxunto de España. En Guisán et al (1995) e (2002) amósase como a porcentaxe da Poboación Galicia/ España pasou do 11\% no ano 1900 , ao $9.6 \%$ en 1950.

No período 1950-2017 a poboación de Galicia manteu un grande estancamento namentres que a de España se incrementaba de forma notable, pasando de 28.17 millóns en 1950 a 46.57 millóns en 2017. A porcentaxe de Poboación Galicia/ España nese período pasou do $9.6 \%$ ao 5.8\%. Galicia tivo unha grande emigración tanto cara ao resto de España como cara ao estranxeiro.

A táboa 1 amosa a evolución da poboación provincial e rexional de Galicia no período 1991-2017 e a táboa 2 amosa o incremento experimentado nos período 1981-2005, 20052010 e 2010-2017.

Táboa 1. Poboación provincial no período 1900-2017

\begin{tabular}{|l|c|c|c|c|c|}
\hline & A Coruña & Lugo & Ourense & Pontevedra & Galicia \\
\hline 1900 & 681895 & 476357 & 419665 & 495721 & 2073638 \\
\hline 1950 & 971641 & 521213 & 494283 & 714666 & 2701803 \\
\hline 2001 & 1096027 & 357648 & 338446 & 903759 & 2695880 \\
\hline 2017 & 1120294 & 333634 & 311680 & 942731 & 2708339 \\
\hline$\% 1900$ & 32.88 & 22.97 & 20.24 & 23.91 & 100 \\
\hline$\% 1950$ & 35.96 & 19.29 & 18.29 & 26.45 & 100 \\
\hline$\% 2011$ & 40.66 & 13.27 & 12.55 & 33.52 & 100 \\
\hline$\% 2017$ & 41.36 & 12.32 & 11.51 & 34.81 & 100 \\
\hline
\end{tabular}

Fonte. IGE e INE

Na táboa 1, observamos que a distribución provincial da poboación modificouse, pasando a provincia de A Coruña de incluír ao 32.88\% da poboación de Galicia en 1900 a unha porcentaxe superior do $41.36 \%$ no ano 2017. A provincia de Pontevedra tamén incrementou a súa participación no total de Galicia, pasando do $23.91 \%$ no ano 1900 ao $34.81 \%$ no ano 2017. As provincias de Lugo e Ourense diminuíron a súa participación no conxunto da poboación de Galicia, pasando Lugo do $22.97 \%$ ao $12.32 \%$ namentres que Ourense diminuía do $20.24 \%$ ao $11.51 \%$.

Táboa 2. Datos provinciais: Poboación, 1981-2017

\begin{tabular}{|l|c|c|c|c|c|c|c|c|}
\hline Provincia & 1981 & 2005 & 2010 & 2017 & $\begin{array}{c}\text { Incr. } \\
1981- \\
2005\end{array}$ & $\begin{array}{c}\text { Incr. } \\
2005- \\
2010\end{array}$ & $\begin{array}{c}\text { Incr. } \\
2010- \\
2017\end{array}$ & $\begin{array}{c}\text { Incr. } \\
1981- \\
2017\end{array}$ \\
\hline Coruña, A & 1093122 & 1126707 & 1146458 & 1120294 & 33585 & 19751 & -26164 & 27172 \\
\hline Lugo & 405377 & 357625 & 353504 & 333634 & -47752 & -4121 & -19870 & -71743 \\
\hline Ourense & 420175 & 339555 & 335219 & 311680 & -80620 & -4336 & -23539 & -108495 \\
\hline Pontevedra & 883268 & 938311 & 962472 & 942731 & 55043 & 24161 & -19741 & 59463 \\
\hline Galicia & 2801942 & 2762198 & 2797653 & 2708339 & -39744 & 35445 & -89314 & -93613 \\
\hline
\end{tabular}

Fonte: Elaborado a partir dos datos do INE incluídos en Guisán (2011) e datos posteriores de IGE e INE. Nota: As derradeiras columnas reflicten o incremento en cada período. 
Observamos un estancamento da poboación galega, cunha diminución de máis de 39 mil habitantes no período 1981-2005, un incremento de máis de 35 mil no período 20052010 e unha diminución de máis de 89 mil no período 2010-2017. Namentres que as provincias de A Coruña e Pontevedra incrementaron a súa poboación, no período 19812017, as de Lugo e Ourense, así como o conxunto de Galicia, experimentaban unha forte diminución.

Evolución do emprego e da renda real por habitante de Galicia

Esta evolución estivo moi relacionada coa evolución do emprego non agrario e do emprego total. Tamén o emprego total aumentou nas provincias occidentais e diminuíu nas provincias orientais.

Nas catro provincias, o emprego non agrario aumentou, pero en Lugo e Ourense o devandito incremento non chegou a compensar a diminución do emprego agrario.

A táboa 3 amosa a evolución do emprego non agrario das provincias galegas no período 1967-2017.

Táboa 3. Evolución do emprego non agrario (miles de persoas)

\begin{tabular}{|c|c|c|c|c|c|}
\hline & A Coruña & Lugo & Ourense & Pontevedra & Galicia \\
\hline 1967 & 180 & 69 & 68 & 158 & 474 \\
\hline 1977 & 253 & 73 & 84 & 227 & 637 \\
\hline 1987 & 249 & 72 & 84 & 205 & 610 \\
\hline 1997 & 298 & 75 & 92 & 240 & 706 \\
\hline 2007 & 462 & 110 & 125 & 394 & 1090 \\
\hline 2017 & 428 & 113 & 103 & 333 & 978 \\
\hline
\end{tabular}

Fonte: Elaboración por M.C. Guisán(2018) a partir dos datos do INE e do IGE.

Os gráficos de Guisán (2018) amosan a evolución do emprego total e do emprego non agrario en cada unha das provincias galegas no período 1964-2017, elaborados a partir de datos da Enquisa da Poboación Activa do INE. O incremento do emprego non agrario nun período de 50 anos (1967-2017) foi de 248 mil persoas na provincia de A Coruña, 175 mil na de Pontevedra, só 45 mil en Lugo e 35 mil en Ourense.

No período 1981-2017, o emprego total e non agrario evolucionou da seguinte forma:

A Coruña: O emprego total incrementouse en 86 mil persoas e o emprego non agrario en 165 mil, pasando de 263 mil en 1981 a 428 mil en 2017.

Lugo: O emprego total disminuíu en 41 mil persoas e o emprego non agrario aumentou en 44 mil., pasando de 69 mil a 113 mil.

Ourense: $O$ emprego total diminuíu en 75 mil persoas e o emprego non agrario aumentou en 28 mil, pasando de 76 mil a 103 mil.

Pontevedra: O emprego total aumentou en 5 mil persoas e o emprego non agrario en 129 mil, pasando de 204 mil a 333 mil.

Como se indica en Guisán (1990), Galicia realizou unha importante modernización do seu sector agrario, especialmente durante a segunda metade do século XX, o que permitiu aumentar a renda por traballador no devandito sector, pero implicou un transvasamento importante do emprego cara sectores non agrarios.

O incremento do emprego non agrario foi importante ata o ano 2008. A crise iniciada en 2008 foi moi prexudicial para a renda e o emprego en Galicia. Isto causou moita emigración interior, entre as bisbarras que crean menos emprego e as que crean un maior número de postos de traballo. Ademais houbo importantes movementos migratorios ao exterior da rexión, que analizamos na vindeira sección a nivel de Galicia. 
Presentamos unha selección de resultados publicados en Guisán (2017) e Guisán e Cancelo (2018).

O gráfico 1 amosa a converxencia de Galicia con España, en VAB industrial real per cápita, durante o período 1992-2014, e con tres países de elevado grao de industrialización.

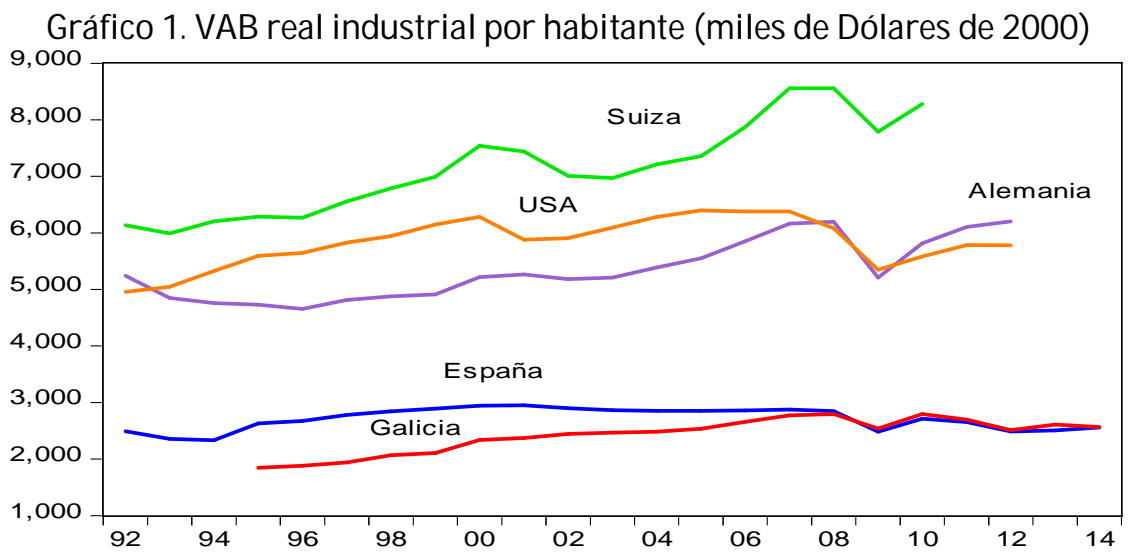

Fonte: Elaborado por Guisán (2017) a partir dos datos do INE e OCDE. Datos de VAB real, conforme ao enfoque produción, en miles de Dólares por habitante, a prezos e tipos de cambio do ano 2000.

Obervamos un esforzo importante en Galicia no período 1994-2008 e un estancamento, da evolución desta variable en España, aínda moi afastada dos niveis de países de maior nivel de renda per cápita, como son Alemaña, os EE. UU. e Suiza.

O gráfico 2 amosa a evolución do emprego non agrario e da renda real por habitante producida no período 1970-2016. Observamos un incremento importante de ámbalas dúas variables ata o ano 2008, unha caída no período 2008-2014 e unha pequena recuperación en 2014-2016.

Trátase dun gráfico dual, no que o eixe vertical da esquerda refírese á variable Emprego non agrario, e o da derecha á Renda real per cápita.

A variable Emprego non agrario aumentou dende menos de 600 mil persoas no ano 1970 a máis dun millón en 2008, diminuíndo de forma importante no período 2008-2014 e aumentando lixeiramente despois do ano 2014. A renda real producida por habitante aumentou en gran medida no período 1970-2008, pasando de algo menos de 6000 Euros, a prezos do ano 2000, en 1970 a un valor que se achega a 15000 no ano 2008. Constátase unha diminución de renda real producida no período 2008-2014, baixando de 14000, e unha lixeira recuperación posterior.

En Guisán (2017 a, b) analizamos as causas da crise económica, que afectou negativamente a todas as CCAA españolas no período 2008-2013 e as outras características que explican a evolución económica de Galicia e España nas derradeiras décadas. Unha das variables máis importantes é o investimento industrial, como xa se indicou en Guisán (1990) e noutros interesantes estudos publicados nesta revista e noutros medios. Galicia realizou un esforzo importante para se achegar ao nivel de España pero o nivel de España sitúase moi por debaixo do que sería desexable para garantir unha converxencia en taxas de emprego e renda per cápita semellantes ás das rexións e países máis avanzados de Europa. 
Gráfico 2. Emprego non agrario e renda real por habitante de Galicia (miles de persoas e Euros a prezos do ano 2000)

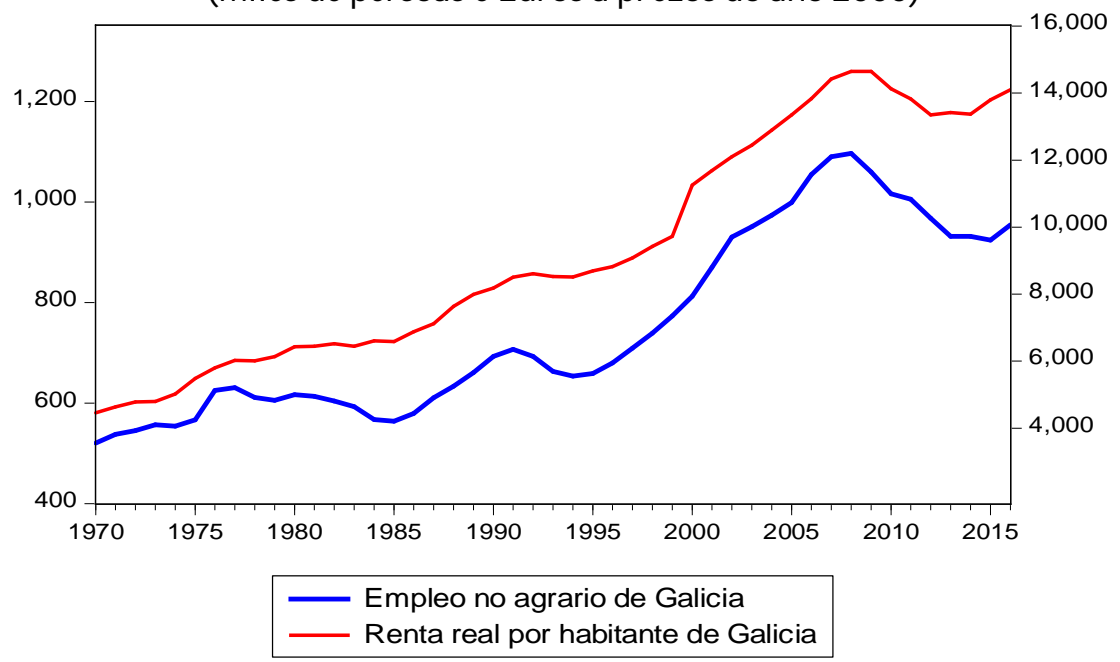

Nota: O eixe esquerdo é a escala do Emprego non agrario (liña inferior de cor azul) o cal evolucionou de menos de 600 mil en 1970 a máis de 1 millón en 2008. O eixe dereito é a escala da Renda real por habitante, a cal evolucionou dende menos de 4000 en 1970 a máis de 10000 en 2008, medido en Euros a prezos do ano 2000. O sector agrario inclúe Agricultura e Pesca. O emprego non agrario inclúe Industria, Construción e Servizos. Fonte: Elaborado por Guisán, M.C. (2018) a partir dos datos do INE e do IGE.

Lopez Viso (2006) cita o libro de Guisán (1990) e comenta: "Como explica Ma del Carmen Guisán na súa análise sobre o emprego en Galicia, cando a economía galega crece a un ritmo importante, prodúcese un incremento do número de empregos non agrarios e un descenso de empregos agrarios, debido a que o aumento do emprego noutros sectores produtivos facilita o transvasamento do exceso da poboación ocupada no sector agrícola a outras actividades. Este transvasamento posibilita un incremento da renda real media dos outros agricultores, e en conxunto é positivo para a economía galega" (Guisán, 1990: 13). Daquí a radical importancia que vai ter para o país galego o proceso de desagrarización das dúas últimas décadas. O nivel de industrialización de Galicia, mesmo triplicado no período 1965-89 é bastante baixo en comparación co correspondente ao dos países da UE. O mesmo pódese afirmar do sector servizos. A pesar de ser un sector que se foi desenvolvendo nos últimos anos presenta en comparación cos países europeos, un nivel menor de actividade e emprego, en relación coa súa poboación, e unha feble presenza de actividades do sector terciario avanzado".

Malia ese importante desenvolvemento industrial, tanto no período 1965-1990, como en 1990-2008, o estancamento posterior da produción industrial per cápita de Galicia e España, tivo repercusións negativas sobre a renda real por habitante e sobre a creación de emprego.

No caso de España o turismo compensa, en parte, o estancamento industrial, pero no caso de Galicia, como se indica en Ferreiro et al (2016), Guisán (2017) e noutros estudos, 0 peso do turismo, mesmo cunha evolución positiva, non é abondo para compensar o estancamento industrial. Galicia precisa incrementar a súa produción industrial ao nivel doutras rexións españolas e europeas máis avanzadas e iso impulsará emprego de calidade en moitos sectores, especialmente nos servizos, e evitará a emigración forzosa da mocidade galega e o declive demográfico. 
Emigración e inmigración de Galicia: resto de España e estranxeiro

Galicia tiña no ano 2017 2.708.339 residentes. No conxunto de España vivían 2.690.328 persoas nadas en Galicia, das cales 2.346.661 residían en Galicia e o resto 343.667 residían noutras CCAA (destacando Madrid con 77.989, Cataluña con 71.564 e País Vasco con 42.742). As cifras do PERE (Padrón de Españoles Residentes no Estranxeiro) inclúen 156.225 nados en Galicia (dos cales 52.106 residen nalgúns dos 5 principais países do destino da emigración laboral dos galegos (Alemaña, Francia, Reino Unido, Suiza e Estados Unidos).

É posible que o PERE non recolla de forma suficiente o número de persoas de nacionalidade española vencelladas a Galicia residentes no estranxeiro (ben sexan nados en Galicia ou non nados en Galicia) pois hai diversos indicadores que amosan rexistros de inmigrantes na seguridade social dalgúns países superiores ás cifras do PERE.

Galicia mantén bastante estable a súa poboación grazas aos movementos inmigratorios que compensan a perda de poboación que se debe á emigración ao resto de España e ao estranxeiro. A emigración total, tanto de nados en Galicia como de inmigrantes, está impulsada cando falla a creación de emprego, especialmente con salarios suficientes para atraer a traballadores con niveis de estudo medios e superiores. En xeral, a emigración dende Galicia ten, de media, un nivel educativo superior á inmigración.

O impulso á industria é fundamental pois non só favorece á demanda e oferta de servizos senón que ademais transmite importantes efectos de incremento da produtividade, de salarios máis elevados para traballadores cualificados e da renda per cápita do conxunto dos cidadáns de Galicia.

A emigración no interior de Galicia continúa sendo intensa, pois no ano 2016, dun total de 88.242 emigracións, 58.710 foron internas no territorio galego e 29.532 foron cara ao resto de España (18.735) e ao estranxeiro (10.787).

A inmigración, procedente do resto de España evolucionou dende 8.523 persoas no ano 2002 ata 19.934 no ano 2016. A inmigración procedente do estranxeiro evolucionou dende 18.186 no ano 2002 ata 15.736 no ano 2016. Guisán e Cancelo (2018) presentan datos anuais do período 2002-2016 correspondente á inmigración e emigración con orixe e destino exterior a Galicia así como aos saldos migratorios.

A poboación residente en Galicia nada fóra de España evolucionou de 123.788 no ano 2002 a 217.244 no ano 2017. Os nados en Latinoamérica supoñen unha parte importante desta poboación inmigrante, xa que pasaron de 47.662 no ano 2002 a 87.683 no ano 2017.

\section{Poboación e emprego nas bisbarras galegas, 1981-2017}

No libro de Guisán et al (2011) inclúese o apéndice D cunha análise da evolución da poboación comarcal de Galicia en 1981-2010, e incorporamos datos do incremento de poboación do devandito estudo nas táboas de datos comarcais seguintes.

As táboas 4.1 a 4.4 amosan a poboación das bisbarras no ano 2017 e o incremento experimentado en 1981-2005, 2005-2010, 2010-2017 e 1981-2017. As táboas do Anexo amosan a evolución da poboación comarcal en 1981-2017, e os gráficos 3.1 a 3.4 amosan a porcentaxe de variación da poboación de cada bisbarra no devandito período.

Provincia de A Coruña: Aumentou a súa poboación en 1981-2017 cun incremento total de 27.172, pero perdeu poboación en 2010-2017. No período 2010-2017, nesta provincia, só aumentaron as bisbarras de A Coruña e Santiago No total do período 81-2017 tamén se incrementou a poboación da bisbarra de Barbanza. 
Táboa 4.1 Datos comarcais de poboación: provincia de A Coruña

\begin{tabular}{|l|l|c|c|c|c|c|}
\hline № & Bisbarra & Pob & Incr & Incr & Inc & Incr \\
& & & $1981-$ & $2005-$ & $2010-$ & Total \\
2005 & 2010 & 2017 & $81-17$ \\
\hline 1 & Arzúa & 16500 & -4264 & -947 & -1049 & -6260 \\
\hline 2 & Barbanza & 66672 & 2220 & 1432 & -1592 & $\mathbf{2 0 6 0}$ \\
\hline 3 & A Barcala & 10414 & -4811 & 28 & -935 & -5718 \\
\hline 4 & Bergantiños & 67357 & -5187 & -212 & -2889 & -8288 \\
\hline 5 & Betanzos & 37975 & -4804 & 383 & -1646 & -6067 \\
\hline 6 & A Coruña & 398730 & 68543 & 17506 & $\mathbf{3 3 1 8}$ & $\mathbf{8 9 3 6 7}$ \\
\hline 7 & Eume & 24834 & -2165 & -1041 & -1885 & -5091 \\
\hline 8 & Ferrol & 154802 & -10591 & -689 & -8178 & -19458 \\
\hline 9 & Fisterra & 21770 & -2499 & -582 & -1974 & -5055 \\
\hline 10 & Muros & 12852 & -4276 & -631 & -1756 & -6663 \\
\hline 11 & Noia & 33527 & -4000 & -538 & -2305 & -6843 \\
\hline 12 & Ordes & 36702 & -2831 & 338 & -2032 & -4525 \\
\hline 13 & Ortegal & 12531 & -5804 & -1446 & -1833 & -9083 \\
\hline 14 & Santiago & 166692 & 25195 & 9051 & $\mathbf{4 7 9 9}$ & $\mathbf{3 9 0 4 5}$ \\
\hline 15 & O Sar & 15922 & -2199 & -368 & -1016 & -3583 \\
\hline 16 & Terra de Melide & 12153 & -2972 & -560 & -1141 & -4673 \\
\hline 17 & Terra de Soneira & 17360 & -3482 & -1064 & -2289 & -6835 \\
\hline 18 & Xallas & 13491 & -2488 & -909 & -1771 & -5168 \\
\hline & Total provincia & 1120294 & 33585 & 19751 & -26164 & $\mathbf{2 7 1 7 2}$ \\
\hline
\end{tabular}

Provincia de Lugo: No período 81-17, esta provincia perdeu 71.743 habitantes, con diminucións tanto no período 1981-2005 como en 2005-2010 e en 2010-2017. No conxunto do período só incrementaron poboación as bisbarras de Lugo e A Mariña Central. No período 2010-2017 ningunha bisbarra tivo unha evolución positiva.

Táboa 4.2. Datos comarcais de poboación: provincia de Lugo

\begin{tabular}{|c|c|c|c|c|c|c|}
\hline № & Bsibarra & $\begin{array}{c}\text { Pob } \\
2017\end{array}$ & $\begin{array}{c}\text { Inc. } \\
1981- \\
2005\end{array}$ & $\begin{array}{c}\text { Inc. } \\
05-10\end{array}$ & $\begin{array}{c}\text { Inc. } \\
10-17\end{array}$ & $\begin{array}{c}\text { Inc. } \\
81-17\end{array}$ \\
\hline 19 & Os Ancares & 10265 & -8298 & -1272 & -1572 & -11142 \\
\hline 20 & Chantada & 13499 & -5223 & -1125 & -1520 & -7868 \\
\hline 21 & Fonsagrada, A & 5185 & -5649 & -756 & -967 & -7372 \\
\hline 22 & Lugo & 118906 & 13749 & 4514 & -1422 & 16841 \\
\hline 23 & Mariña Central, A & 29185 & 5168 & 342 & -1516 & 3994 \\
\hline 24 & Mariña Occident, A & 25929 & -6111 & -106 & -1525 & -7742 \\
\hline 25 & Mariña Oriental, A & 16357 & -2631 & 54 & -965 & -3542 \\
\hline 26 & Meira & 5231 & -2760 & -466 & -517 & -3743 \\
\hline 27 & Quiroga & 5333 & -3397 & -703 & -764 & -4864 \\
\hline 28 & Sarria & 22994 & -5253 & -788 & -1703 & -7744 \\
\hline 29 & Terra Chá & 40770 & -11400 & -2046 & -3872 & -17318 \\
\hline 30 & Terra de Lemos & 30754 & -11134 & -1290 & -2597 & -15021 \\
\hline 31 & Ulloa, A & 9226 & -4813 & -479 & -930 & -6222 \\
\hline & Total provincia & 333634 & -47752 & -4121 & -19870 & -71743 \\
\hline
\end{tabular}

Provincia de Ourense: Esta provincia perdeu 118.495 habitantes no período 1981-2017. A maior diminución de poboación producíuse no período 1981-2005, coa perda de 90.620 
habitantes. Só a bisbarra de Ourense tivo un incremento de poboación no período 19812017. Os maiores descensos de poboación nese período producíronse en A Limia (cun descenso de 20.822 habitantes), e Terra de Celanova (cun descenso de 21.287 habitantes).

Táboa 4.3. Datos comarcais de poboación. provincia de Ourense

\begin{tabular}{|l|l|r|c|c|c|c|}
\hline № & Bisbarra & $\begin{array}{c}\text { Poboación } \\
2017\end{array}$ & $\begin{array}{c}\text { Incr. } \\
1981- \\
2005\end{array}$ & $\begin{array}{c}\text { Incr. } \\
2005-\end{array}$ & $\begin{array}{c}\text { Incr. } \\
2010\end{array}$ & $\begin{array}{c}\text { Incr. } \\
1981- \\
2017\end{array}$ \\
\hline 32 & Allariz-Maceda & 14181 & -6262 & 35 & -974 & -7201 \\
\hline 33 & Baixa Limia & 6936 & -9867 & -726 & -1583 & -12176 \\
\hline 34 & Carballiño, O & 26765 & -8794 & -445 & -2642 & -11881 \\
\hline 35 & Limia, A & 20658 & -17214 & -891 & -2717 & -20822 \\
\hline 36 & Ourense & 144011 & 12067 & 2344 & -2615 & 11796 \\
\hline 37 & Ribeiro, O & 16336 & -11230 & -1082 & -2736 & -15048 \\
\hline 38 & Terra de Caldelas & 2990 & -5591 & -553 & -660 & -6804 \\
\hline 39 & Terra de Celanova & 17620 & -16944 & -1151 & -3192 & -21287 \\
\hline 40 & Terra de Trives & 4111 & -5767 & -595 & -767 & -7129 \\
\hline 41 & Valdeorras & 26134 & -5420 & -767 & -2083 & -8270 \\
\hline 42 & Verín & 26022 & -10578 & -101 & -2574 & -13253 \\
\hline 43 & Viana & 5916 & -5020 & -404 & -996 & -6420 \\
\hline & Total provincia & 311680 & -90620 & -4336 & -23539 & -118495 \\
\hline
\end{tabular}

Provincia de Pontevedra: Incrementou a súa poboación no período 1981-2017 en 59.463 persoas, destacando Vigo cun incremento de 56.170 e Pontevedra cun incremento de 17.558. Tiveron tamén unha evolución positiva O Baixo Miño (cun incremento de 5.718), O Condado (cun incremento de 2.473), O Morrazo (cun incremento de 7.542) e O Salnés (cun incremento de 10.959.

Táboa 4.4. Datos comarcales de poboación: provincia de Pontevedra

\begin{tabular}{|l|l|r|c|r|r|r|}
\hline & & 2017 & $\begin{array}{c}\text { Incr. } \\
1981-\end{array}$ & $\begin{array}{c}\text { Incr. } \\
2005-\end{array}$ & $\begin{array}{c}\text { Incr. } \\
2010-\end{array}$ & $\begin{array}{c}\text { Incr. } \\
1981- \\
2005\end{array}$ \\
& & & 2010 & 2017 & 2017 \\
\hline 44 & Baixo Miño,O & 49828 & 3932 & 3020 & -1234 & $\mathbf{5 7 1 8}$ \\
\hline 45 & Caldas & 34197 & -1505 & 203 & -1214 & -2516 \\
\hline 46 & Condado, O & 41693 & 972 & 2943 & -1442 & $\mathbf{2 4 7 3}$ \\
\hline 47 & Deza & 40310 & -5327 & -559 & -4459 & -10345 \\
\hline 48 & Morrazo, O & 82711 & 6726 & 1614 & -798 & $\mathbf{7 5 4 2}$ \\
\hline 49 & Paradanta, A & 12531 & -7963 & -921 & -3668 & -12552 \\
\hline 50 & Pontevedra & 125278 & 12261 & 3752 & $\mathbf{1 5 4 5}$ & $\mathbf{1 7 5 5 8}$ \\
\hline 51 & Salnés, O & 109882 & 8615 & 4225 & -1881 & $\mathbf{1 0 9 5 9}$ \\
\hline 52 & Tabeirós-Terra de Montes & 24223 & -10756 & -776 & -4012 & -15544 \\
\hline 53 & Vigo & 422078 & 48088 & 10660 & -2578 & $\mathbf{5 6 1 7 0}$ \\
\hline & Total Provincia & 942731 & 55043 & 24161 & -19741 & $\mathbf{5 9 4 6 3}$ \\
\hline
\end{tabular}

En resumo, Galicia experimentou no período analizado, fortes movementos migratorios internos debido á despoboación de moitas comarcas. O incremento das emigracións exteriores de persoas nadas en Galicia (cara ao resto de España e ao estranxeiro) no período 2002-2017, viuse compensado co incremento de inmigracións de persoas estranxeiras procedentes do resto de España e do estranxeiro. Isto conseguiu manter a poboación de Galicia en niveis próximos a 2.7 millóns. 
A profesora M.C. Guisán publicou unha Tribuna de Opinión, en La Voz de Galicia no ano 1984, titulada "Crise económica e emigración interior en Galicia", na que se destacaba a necesidade de formular e impulsar un plan económico comarcal de creación de emprego. A partir do devandito artigo, esta profesora e outros investigadores tratamos de fomentar medidas de impulso ao emprego a través dos libros de Guisán (1990) e de Guisán, Aguayo e Expósito (2011), e outras iniciativas, como se indica no Anexo. Conseguimos algúns resultados positivos pero non tantos como sería posible e desexable.

\section{Relación entre emprego e poboación a nivel comarcal}

O gráfico 3 amosa o incremento da poboación nas bisbarras 2011-2017. A orde númerica das bisbarras é a que figura nas táboas 4.1 a 4.4 e na táboa 5. A maioría ten un incremento negativo, xa que a poboación no ano 2017 foi inferior á do ano 2011, namentres o gráfico 4 amosa o incremento do emprego no devandito período.

\section{Gráfico 3. Incremento da Poboación: Bisbarras de Galícia 2011-2017}

Incremento de Población: Comarcas de Galicia 2011-2017

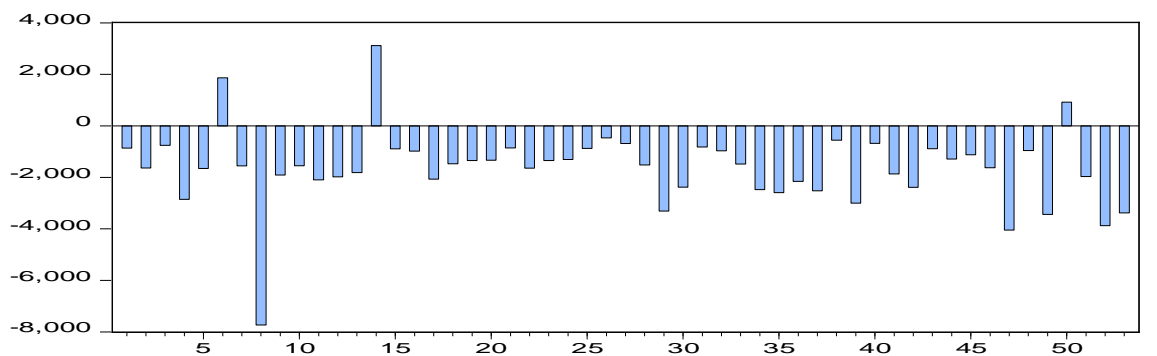

Fonte: Elaboración a partir dos datos da táboa 5. Datos do IGE e Seguridade Social.

Gráfico 4. Incremento de Afiliacións: Bisbarras de Galicia 2011-2017

Incremento de Afiliaciones a la Seguridad Social: Comarcas de Galicia, 2011-2017

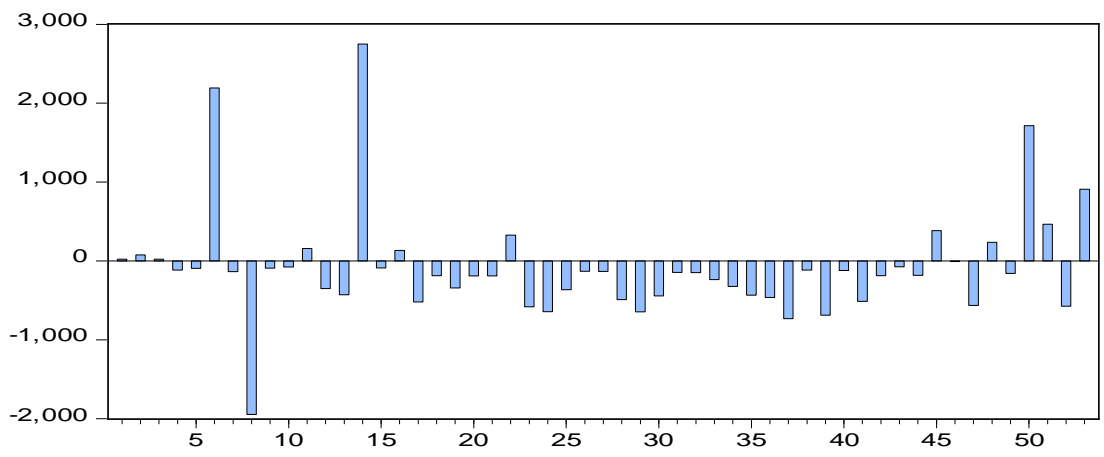

A táboa 5 presenta a evolución da poboación comarcal e do número de traballadores afiliados á seguridade social no período 2011-2017. Incluímos tamén na devandita táboa o número de afiliacións no ano 2006 para poder ver a evolución do emprego no período 2006-2017.

Táboa 5. Poboación 2011-217 e Afiliacións á seguridade social en 2006-2017

\begin{tabular}{|l|l|r|r|r|r|r|}
\hline & & Pob2011 & Pob2017 & Afilia2006 & Afilia2011 & Afilia2017 \\
\hline $\mathbf{1}$ & Arzúa & 17364 & 16500 & 6602 & 6294 & 6317 \\
\hline $\mathbf{2}$ & Barbanza & 68311 & 66672 & 23118 & 21918 & 21993 \\
\hline $\mathbf{3}$ & A Barcala & 11179 & 10424 & 3775 & 3643 & 3664 \\
\hline $\mathbf{4}$ & Bergantiños & 70209 & 67357 & 26980 & 24588 & 24471 \\
\hline $\mathbf{5}$ & Betanzos & 39632 & 37975 & 14207 & 14476 & 14381 \\
\hline
\end{tabular}




\begin{tabular}{|c|c|c|c|c|c|c|}
\hline 6 & A Coruña & 396864 & 398730 & 151042 & 149069 & 151263 \\
\hline 7 & Eume & 26391 & 24834 & 9536 & 8622 & 8485 \\
\hline 8 & Ferrol & 162531 & 154802 & 51615 & 49525 & 47578 \\
\hline 9 & Fisterra & 23677 & 21770 & 7166 & 6927 & 6835 \\
\hline 10 & Muros & 14399 & 12852 & 4163 & 3657 & 3581 \\
\hline 11 & Noia & 35623 & 33527 & 11279 & 10775 & 10932 \\
\hline 12 & Ordes & 38683 & 36702 & 15448 & 15291 & 14942 \\
\hline 13 & Ortegal & 14347 & 12531 & 4781 & 4202 & 3772 \\
\hline 14 & Santiago & 163576 & 166692 & 61545 & 63569 & 66318 \\
\hline 15 & O Sar & 16814 & 15922 & 6409 & 5833 & 5745 \\
\hline 16 & Terra de Melide & 13137 & 12153 & 4394 & 4351 & 4483 \\
\hline 27 & Terra de Soneira & 19426 & 17360 & 6853 & 6146 & 5627 \\
\hline 18 & Xallas & 14961 & 13491 & 5593 & 4962 & 4775 \\
\hline 19 & Os Ancares & 11612 & 10265 & 4099 & 3902 & 3558 \\
\hline 20 & Chantada & 14835 & 13499 & 5067 & 5041 & 4851 \\
\hline 21 & A Fonsagrada & 6043 & 5185 & 2208 & 1982 & 1792 \\
\hline 22 & Lugo & 120548 & 118906 & 46325 & 44882 & 45209 \\
\hline 23 & A Mariña Central & 30530 & 29185 & 11610 & 11477 & 10896 \\
\hline 24 & A Mariña Occid & 27238 & 25929 & 10228 & 9746 & 9102 \\
\hline 25 & A Mariña Oriental & 17231 & 16357 & 6088 & 5902 & 5537 \\
\hline 26 & Meira & 5698 & 5231 & 2297 & 2059 & 1929 \\
\hline 27 & Quiroga & 6020 & 5333 & 1784 & 1601 & 1468 \\
\hline 28 & Sarria & 24511 & 22994 & 9231 & 8921 & 8430 \\
\hline 29 & Terra Chá & 44081 & 40770 & 16772 & 15953 & 15306 \\
\hline 30 & Terra de Lemos & 33133 & 30754 & 9872 & 9791 & 9346 \\
\hline 31 & A Ulloa & 10050 & 9226 & 3155 & 3263 & 3118 \\
\hline 32 & Allariz-Maceda & 15151 & 14181 & 4181 & 4824 & 4677 \\
\hline 33 & Baixa Limia & 8421 & 6936 & 1813 & 2043 & 1805 \\
\hline 34 & 0 Carballiño & 29240 & 26765 & 8416 & 8569 & 8246 \\
\hline 35 & A Limia & 23252 & 20658 & 6485 & 6668 & 6233 \\
\hline 36 & Ourense & 146165 & 144011 & 55622 & 51425 & 50961 \\
\hline 37 & O Ribeiro & 18861 & 16336 & 5258 & 5255 & 4523 \\
\hline 38 & Terra de Caldelas & 3544 & 2990 & 1012 & 1055 & 939 \\
\hline 39 & Terra de Celanova & 20623 & 17620 & 5249 & 5435 & 4746 \\
\hline 40 & Terra de Trives & 4789 & 4111 & 1477 & 1431 & 1309 \\
\hline 41 & Valdeorras & 27999 & 26134 & 8799 & 8640 & 8127 \\
\hline 42 & Verín & 28410 & 26022 & 6858 & 6830 & 6642 \\
\hline 43 & Viana & 6802 & 5916 & 1859 & 1858 & 1783 \\
\hline 44 & O Baixo Miño & 51116 & 49828 & 17967 & 17065 & 16883 \\
\hline 45 & Caldas & 35322 & 34197 & 12876 & 11652 & 12037 \\
\hline 46 & O Condado & 43318 & 41693 & 13202 & 13890 & 13882 \\
\hline 47 & Deza & 44355 & 40310 & 16765 & 15484 & 14920 \\
\hline 48 & O Morrazo & 83669 & 82711 & 28666 & 26769 & 27005 \\
\hline 49 & A Paradanta & 15970 & 12531 & 3478 & 3690 & 3532 \\
\hline 50 & Pontevedra & 124356 & 125278 & 44674 & 40865 & 42579 \\
\hline 51 & O Salnés & 111849 & 109882 & 41583 & 38721 & 39186 \\
\hline 52 & $\begin{array}{l}\text { Tabeirós-Terra de } \\
\text { Montes }\end{array}$ & 28100 & 24223 & 10054 & 9108 & 8534 \\
\hline 53 & Vigo & 425456 & 422078 & 169076 & 152981 & 153890 \\
\hline & Total Galicia & & & & & \\
\hline
\end{tabular}

Nota. Pob=Poboación. Afilia: Número de traballadores medido polas afiliacións á Seguridade

Social. Fonte. Elaboración a partir de datos do IGE e da Seguridade Social. 
No período 2011-2017 todas as comarcas, agás tres, tiveron perda de poboación. As 3 bisbarras con incremento no devandito período foron A Coruña, Santiago e Pontevedra.

A correlación positiva entre o número de afiliados á seguridade social e a poboación das bisbarras de Galicia é moi elevada, cun coeficiente de correlación lineal entre ámbalas dúas variables de 0.9980 no ano 2011 e de 0.9981 no ano 2017.

En Guisán, Aguayo e Expósito (2011) amósase que no período 2005-2010 houbo unha evolución poboacional máis positiva nalgunhas bisbarras que tiveron unha maior creación de emprego e é previsible que a superación da crise económica do período 2008-2017 poida permitir de novo unha evolución positiva.

Gráfico 5. Bisbarras con aumento de Poboación en 2005-2010 (miles de persoas)

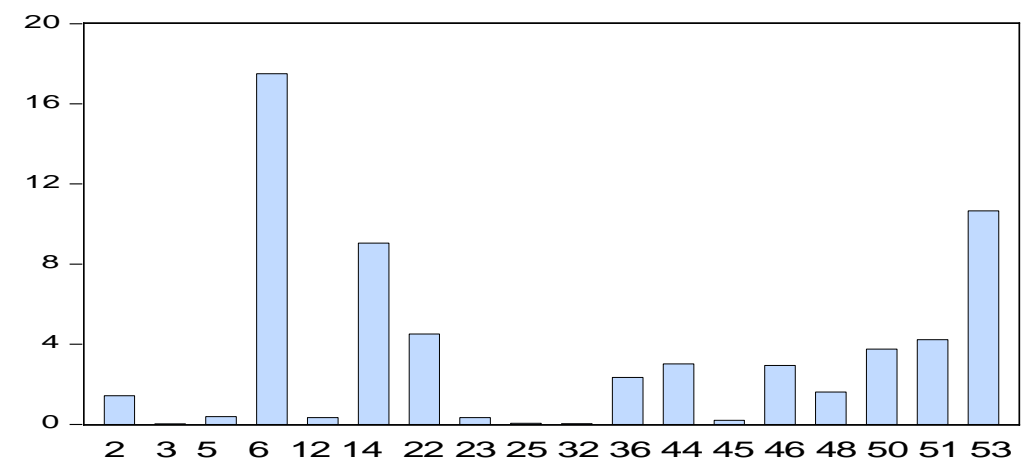

As bisbarras máis destacadas por incremento de poboación no período 2005-2010 foron A Coruña, Vigo e Santiago.

Na provincia de A Coruña 7 das 18 bisbarras tiveron un aumento de poboación nese período: 2 Barbanza, 3 A Barcala, 5 Betanzos, 6 A Coruña, 12 Ordes e 14 Santiago.

Na provincia de Lugo só 3 das 13 bisbarras tiveron un aumento de poboación nese período: 22 Lugo, 23 Mariña Central, 25 Mariña Oriental.

Na provincia de Ourense só 2 das 22 bisbarras tiveron un aumento de poboación nese período: 32 Allariz-Maceda e 36 Ourense.

Na provincia de Pontevedra 7 das súas 11 bisbarras tiveron un incremento de poboación no período 2005-2010: 44 Baixo Miño, 45 Caldas, 46 Condado, 48 Morrazo, 50 Pontevedra, 51 O Salnés e 53 Vigo.

\section{Modelo econométrico}

Hai varios factores que inflúen no aumento ou diminución da poboación a nivel comarcal (destino de xubilados, prezo da vivenda, etc.), pero o máis importante de todos en xeral é a creación de emprego. O noso modelo relaciona a poboación das bisbarras co número de afiliacións á seguridade social.

Estimamos unha ecuación para o ano 2011 e outra para o ano 2017, cos datos das 53 bisbarras de Galicia, relacionando a Poboación co número de afiliacións á seguridade social. O efecto é positivo e altamente significativo. Na ecuación 1 incluímos dúas variables ficticias, unha para a bisbarra 6 (A Coruña) e outra para a bisbarra 8 (Ferrol) ao amosar ámbalas dúas bisbarras circunstancias particulares. Na ecuación 2, do ano 2017, xa non foi significativa a variable ficticia de A Coruña (D6), e só foi preciso incluír a variable ficticia de Ferrol (D8). A bisbarra de Ferrol amosa un nivel de poboación superior ao que lle correspondería polo número de traballadores, o cal se pode deber a varios factores, como a existencia dun núcleo poboacional importante de persoas xubiladas nesa cidade, ou ao feito de que poida haber desprazamentos diarios de traballadores a outras comarcas. 
Ecuación 1. Modelo econométrico que relaciona Pob11 con Afilia11 Dependent Variable: POB11. Method: Least Squares. Sample: 153

\begin{tabular}{|l|r|r|r|r|}
\hline \multicolumn{1}{|c|}{ Variable } & Coefficient & Std. Error & t-Statistic & \multicolumn{1}{c|}{ Prob. } \\
\hline AFILIA11 & 2.801440 & 0.021381 & 131.0247 & 0.0000 \\
\hline D6 & -20743.88 & 5333.125 & -3.889630 & 0.0003 \\
\hline D8 & 23789.68 & 4405.104 & 5.400479 & 0.0000 \\
\hline R-squared & 0.997398 & \multicolumn{2}{|c|}{ Mean dependent var } & 52743.81 \\
\hline Adjusted R-squared & 0.997293 & \multicolumn{2}{|c|}{ S.D. dependent var } & 82190.55 \\
\hline S.E. of regression & 4275.943 & Akaike info criterion & 19.61434 \\
\hline Sum squared resid & $9.14 \mathrm{E}+08$ & \multicolumn{2}{|c|}{ Schwarz criterion } & 19.72586 \\
\hline Log likelihood & -516.7799 & \multicolumn{2}{|l}{} & 19.65722 \\
\hline Durbin-Watson & 1.369035 & \multicolumn{3}{|l}{} \\
\hline
\end{tabular}

Ecuación 2. Modelo econométrico que relaciona Pob17 con Afilia17

\begin{tabular}{|l|r|r|r|r|}
\hline \multicolumn{5}{|c|}{ Dependent Variable: POB17. Method: Least Squares. Sample: 153} \\
\hline \multicolumn{1}{|c|}{ Variable } & Coefficient & Std. Error & t-Statistic & Prob. \\
\hline AFILIA17 & 2.707361 & 0.016953 & 159.7021 & 0.0000 \\
\hline D8 & 25991.16 & 4348.034 & 5.977681 & 0.0000 \\
\hline R-squared & 0.997356 & Mean dependent var & 51100.74 \\
\hline Adjusted R-squared & 0.997304 & \multicolumn{2}{|c|}{ S.D. dependent var } & 82284.92 \\
\hline S.E. of regression & 4272.569 & Akaike info criterion & 19.59482 \\
\hline Sum squared resid & $9.31 E+08$ & \multicolumn{2}{|c|}{ Schwarz criterion } & 19.66917 \\
\hline Log likelihood & -517.2628 & \multicolumn{4}{|c|}{ Hannan-Quinn criter. } & 19.62342 \\
\hline Durbin-Watson stat & 1.517652 & & & \\
\hline
\end{tabular}

Os resultados amosan o importante impacto positivo e significativo que ten o emprego comarcal sobre a poboación comarcal. A bondade do axuste é moi elevada en ámbolos dous anos.

Factores importantes para impulsar o emprego non agrario

En varios estudos citados na bibliografía destacan varios factores importantes para impulsar o emprego comarcal. Así en Guisán (1990) e en Guisán, Aguayo e Expósito (2011) destácase a grande importancia que ten o impulso ao desenvolvemento industrial, namentres que en Guisán, Aguayo e Neira (2007) e en Ferreiro et al (2016) destácase a conveniencia de impulsar tamén o sector turístico, e en varios estudos, como os de Vence, citados en Guisán (2015) destácase a importancia de impulsar o gasto en I+D ao servizo do desenvolvemento económico, tema no que lamentablemente non avanzamos o suficiente. No informe do CES (2017) analízanse diversas políticas económicas que conveñen impulsar para contribuír ao impulso do desenvolvemento industrial pero polo de agora non se adoptaron medidas suficientes nesa dirección.

En Guisán et al (2011) sinalabamos: "Dado que os estudos rexionais e comarcais indican que a industria é en xeral o sector motor do emprego, ao xerar non só emprego directo senón tamén numerosos empregos indirectos na construción e nos servizos, está claro que a meirande parte das bisbarras de Galicia necesitan un plan de industrialización adaptado ás súas circunstancias medioambientais e de capital humano. Existen moitas medidas que poden potenciar ese dinamismo, especialmente as relacionadas co desenvolvemento industrial, o capital humano e as que potencian a creación de emprego. 
O desenvolvemento industrial é abondo, en xeral, para garantir un desenvolvemento sostible da construción e dos servizos, conducindo a un incremento da renda real por habitante e unha mellora das taxas de emprego de ámbolos dous sectores.

\section{Conclusións}

Galicia é unha rexión con excelentes atractivos para unha boa calidade de vida, pero lamentablemente moitos traballadores teñen que emigrar debido á insuficiente creación de emprego. Namentres unha parte importante da mocidade con estudos superiores emigra fóra da rexión (a outras rexións españolas ou ao estranxeiro) para conseguir oportunidades de traballo cualificado e mellores condicións laborais, ocorre que Galicia recibe emigrantes procedentes de países con menor nivel de renda per cápita. Como consecuencia destes movementos, o número de habitantes está estabilizado, con certa tendencia a diminuír debido tamén a un grao importante de avellentamento.

Aínda cando a poboación se estabilice hai un problema importante de emigración interior a nivel comarcal, que foi o obxecto principal deste estudo. No período 2011-2017 só 3 bisbarras aumentaron a súa poboación (A Coruña, Santiago e Pontevedra), namentres que as outras 50 perderon poboación. O descenso de poboación no período 1981-2017 foi moi elevado en moitas bisbarras e é moi importante que a poboación se estabilice e mesmo se incremente en todas elas.

Levamos moitos años, alomenos dende 1984 propoñendo solucións eficaces para este importante problema de Galicia. Lamentablemente non existe unha suficiente cooperación de institucións públicas e privadas para apoiar iniciativas de investigadoras e investigadores das universidades de Galicia para impulsar o desenvolvemento industrial de Galicia e o gasto en investigación, pois son dous factores básicos para impulsar os sectores de servizos, a renda real e o emprego en todas as bisbarras galegas. Evidentemente houbo avances que permitiron unha converxencia de Galicia coa media española a nivel de produción real por habitante da industria, pero dado que a media española se quedou estancada en relación cos países e rexións máis avanzados de Europa, é preciso un impulso especial a estas políticas en Galicia. Tamén é interesante impulsar o turismo.

\section{Bibliografía}

Aldrey,JA., Del Río,D. (2016). Crónica de un envejecimiento anunciado: Galicia 2015-2030. XIV Congreso Nacional de Población AGE, Sevilla. Disponible en:http:/ / envejecimiento. csic.es/ documentos/ documentos/ agepoblacion-congresossevilla-02-2015.pdf

Barreiro, X.L., Pascual, R M, Y Araujo, L, R.(2013): O reto demográfico de Galicia, Escola Galega de Administración Pública (Santiago de Compostela),

Consello Galego de Relacións Laborais (2008). A muller na poboación galega. Capítulo 5 del Informe Socio-laboral 2008. Disponible en http:// cgrl.xunta.es/ revista/ isl2008_5.pdf CES(2017). Por unha alianza no sector industrial galego. Informe, disponible en: http:/ / www.ces-galicia.org/ publicacions/ informes/ alianza-no-sector-industrial-galego

Ferreiro-Seoane, F.J., Vaquero-García, A., Camino Santos, M. (2016). “Un estudio comarcal de la actividad turística em Galicia a partir de indicadores". Papers de Turisme, no 59.

IGE. Base estadística de Galicia. Varios años.

INE. Base estadística de España y CCAA. Varios años.

Guisán, M.C.(1990). Galicia 2000. Industria y Empleo. Libro publicado por el Servicio de Publicaciones de la USC, disponible on line en: http:/ / www.usc.es/ economet/ galicia.htm

Guisán, M.C. (1996): “La Europa de las regiones y la convergencia española”. Revista Galega de Economía, vol. 5, no 2, pp. 133-150.1 
Guisán, M.C., Aguayo, E., Neira. I.(1999). Economía del Turismo en Galicia. Libro EE3 de la Asociación Hispalink-Galicia. Disponible en: : http:/ / www.usc.es/ economet/ galicia.htm Guisán, M.C. (2011). “Empleo, población, industria y desarrollo económico en Europa: Análisis comparativo de España, Alemania, Francia, Italia y Gran Bretaña, en 1960-2010 y perspectivas 2011-2020". Revista Galega de Economía, Vol. 20-3, Extra. ${ }^{1}$

Guisán, M .C. (2011), coord.. Emprego sectorial e participación social das mulleres en Galicia e Europa. Servicio de Publicaciones de la USC.

Guisan, M.C. (2017 b). “La economía de Galicia y España en 2007-2017: diez años de crisis y recuperación, Revista Galega de Economía, Vol. 26-1.1

Guisán, M.C. (2017 a). Desarrollo económico regional de España, 1986-2013: 25 años de evolución. Revista Galega de Economía, Vol. 26-2.1

Guisán, M.C., Aguayo, E.(2009). Empleo y producción en Galicia en el período 2001-2008. Efectos de la industria y el turismo sobre los sectores de Servicios. Revista Galega de Economía, Vol. 18-2, disponible on line. ${ }^{1}$

Guisán, M.C., Aguayo, E., Neira, I. (1999). Economía del turismo en Galicia. Impacto económico y distribución territorial. Libro EE3, de Estudios Económicos de la Asociación Hispalink-Galicia, disponible on line en http:// www.usc.es/ economet/ galicia.htm

Guisán, M.C., Cancelo, M.T. (2018). “Principales indicadores económicos de Galicia: evolución y situación actual". Comunicación presentada al Congreso 50 Años de Estudios de Economía en Galicia, publicada en Revista Galega de Economía, Vol. 27-3.1

Guisan, M.C., Cancelo, M.T., Iglesias, A., Vazquez-Rozas, E. (1995). "Perspectivas demográficas de Galicia”, Documento ํo 53 de la serie "Economic Development". 2

López Viso, M. (2006). El Fondo Social Europeo: escenarios y nuevos retos en el marco de la actual Unión Europea. Revista de Estudios Europeos, REE 43 (Mayo-Agosto 2006) Instituto de Estudios Europeos, en: http:/ / ieeblogsuvaes/ 2a-epoca-a-partir-del-no-26/

Pazo, A.J., Moragón, M.P. Cartografía del despoblamiento en Galicia a escala parroquial.

Revista de Investigación en Educación, https:/ / dialnetuniriojaes/ descarga/ articulo/ 4729596pdf despoblamiento en

Otero, L., Fernández, S., Vivel, M., Reyes, S.(2007). Aproximación empírica a los problemas financieros de la PYME industrial gallega. Revista Galega de Economia, Vol. 16-2.

Pena Trapero, B.J., coord..(1975). Análisis y proyección de los recursos humanos de Galicia. Trabajo realizado por el Equipo de Econometría de la USC, publicado por el INE.

Rodil, O. (2008). La inserción de las economías periféricas en el nuevo patrón de comercio intra-industrial: el caso de la economía gallega (1988-2005). Revista Galega de Economía, Vol. 17.1

Rodríguez González, R (Dir) (2004): Os concellos galegos para o século XXI Análise dunha reestructuración do territorio e do goberno local, USC, IDEGA, Santiago de Compostela,

SANCHEZ-CARREIRA, M.C. (2009). El papel de la empresa pública industrial en el desarrollo regional. Revista Galega de Economia Vol- 18-1.3

Vence, X. (2010). Políticas de innovación en Galicia. Balance de una década. Revista Galega de Economia, Volumen 19-3, extra

Prensa: Artículo de Guisán, María-Carmen(1984). Tribuna. Crisis económica y emigración interior en Galicia. Voz de Galicia, Miércoles 18 de abril de 1984, y otras notas de prensa sobre economía gallega e informes en : http:/ / www.usc.es/ economet/ galicia.htm

1 Revista Galega de Economía: http:/ / www.usc.es/ econo/ RGE/ benvidag.htm

2 http:/ / www.usc.es/ economet/ econometria.htm

Anexo on line en Ideas Repec: https:/ / ideas.repec.org/ s/ sdo/ regaec.html 